\title{
АРХАИКА В ОБЕСПЕЧЕНИИ СПРАВЕДЛИВОСТИ В РОССИИ
}

\author{
В.Л. Римский \\ (vlrim@yandex.ru) \\ Московский психолого-соицальный университет, \\ Москва, Россия
}

Цитирование: Римский В.Л. Архаика в обеспечении справедливости в России // Власть и элиты. 2020. Т. 7, № 2. С. 129-152.

DOI: https://doi.org/10.31119/pe.2020.7.2.6

\begin{abstract}
Аннотация. Представлены проявления архаики в обеспечении справедливости в современной России. Обоснования этих проявлений основаны на результатах эмпирических соииологических исследований справедливости в российском обществе, которые осуществлялись в 2019 и 2020 г2. Показано, что российская архаика во многом определяется совместным действием трех факторов: доминированием профессионально-именного кода М.К. Петрова, сословностью и раздаточной экономикой. При этом ведушую роль в закреплении архаики в соииальных практиках справедливости играют высшие должностные тица органов власти. Приведены примеры проявлений архаики в обеспечении справедливости в период эпидемии коронавируса COVID-19.

Ключевые слова: справедливость, несправедливость, архаика, сословность, раздаточная экономика, профессионально-именной соииокод.
\end{abstract}

\section{МЕТОДОЛОГИЯ И МЕТОДИКИ ИССЛЕДОВАНИЙ}

В статье кратко описаны проявления архаики в обеспечении справедливости в современной России. Суждения основаны на результатах двух взаимосвязанных социологических исследований справедливости в российском обществе, проведенных в сентябре-ноябре 2019 г. и в октябре 2020 г. $^{1}$ Целями этих исследований были изучение принципов

${ }^{1}$ Исследования выполнены в рамках исследовательских проектов № 19011-31443 «Общественный запрос на справедливость и ее обеспечение со стороны государства» и № 20-011-31240 «Справедливость в повседневной жизни и в образе будущего российского общества» при финансовой поддержке РФФИ и АНО ЭИСИ. 
и критериев справедливости, которые российские граждане используют в различных жизненных ситуациях для оценивания как собственных, так и чужих социальных практик, а также их аргументов и обоснований того, что считать справедливым и несправедливым. Методология этих исследований была основана на теории справедливости Болтански и Тевено [Болтански, Тевено 2013], а также на концепции режимов вовлеченности в обоснования справедливости Тевено [Тевено 2006; Thévenot 2006]. Конкретными методиками в исследовании 2019 г. были настольный анализ ранее проведенных исследований, поисковый телефонный опрос на выборке из 200 респондентов, фокус-группы и глубинные полуформализованных интервью с гражданами [Римский 2019]. В исследовании 2020 г. конкретными методиками были настольный анализ и массовый телефонный анкетный опрос граждан по репрезентативной российской выборке из 512 законченных интервью.

Проекты 2019 и 2020 гг. стали продолжением и развитием исследования справедливости, выполненного Фондом ИНДЕМ в 2013-2015 гг. Целями работы Фонда ИНДЕМ были изучение представлений о справедливости в сознании российских граждан, а также того, как эти представления используются в социальных практиках. Методология исследования 2013-2015 гг. также основывалась на теории справедливости Болтански и Тевено, а в качестве конкретных методик в нем применялись настольный анализ ранее проведенных исследований, полуформализованные экспертные интервью, фокус-группы и массовый анкетный опрос граждан по репрезентативной российской выборке из 2058 законченных интервью [Римский 2016а; 2016b].

\section{МИРЫ СПРАВЕДЛИВОСТИ БОЛТАНСКИ И ТЕВЕНО}

Болтански и Тевено в своей социологической теории анализировали справедливость не как совокупность тех или иных абстрактных идей, а как практические способности индивидов определять, какие принципы и критерии справедливости можно или нужно применять в тех или иных жизненных ситуациях. Через осмысление изученных ими практик разрешений трудовых споров во Франции Болтански и Тевено сформулировали концепцию миров справедливости, в каждом из которых индивиды используют характерную именно для этого мира логику обоснования справедливости, отличающуюся от используемых ими логик для других миров. При этом индивиды вполне способны в об- 
суждении одной жизненной ситуации переключаться от логики одного мира справедливости к логике другого, и делают это нередко весьма продуктивно для обоснований справедливости. Так, индивиды не только используют миры справедливости, но и участвуют в конструировании реальных социальных практик, характерных для каждого из них. В результате миры справедливости конструируются не только теоретиками - философами, социологами, политологами, но и всеми индивидами, использующими те или иные принципы, критерии, материальные объекты (вещи) и обстоятельства для оценивания и обоснования справедливости в этих мирах. Но такое разделение логики, принципов и критериев справедливости по нескольким мирам повышает для индивидов уровень сложности обоснований справедливости в конкретных жизненных ситуациях и достижения согласий по ним [Болтански, Тевено 2013: 79].

Болтански и Тевено в своей теории справедливости предложили различать шесть миров справедливости с указанием на то, что их число может быть увеличено по результатам последующих исследований. В наших исследованиях шести миров справедливости Болтански и Тевено оказалось вполне достаточно для различения используемых российскими гражданами в их повседневности принципов и критериев справедливости. Эти шесть миров справедливости для конструирования конкретных методик эмпирических исследований были концептуализированы с учетом российских реалий и получили основные характеристики [Болтански, Тевено 2013: 252-328; Ковенева 2008: 11-14; Наумова 2014: 248].

\section{Мир вдохновения}

В мире вдохновения справедливость определяется способностями индивидов отдаться вдохновению, а потому малозначимы правила поведения в реальном мире, следование социальным иерархиям, законам, ориентации на денежные измерения ценностей и т.п. В этом мире вполне допустимы внутренние психические испытания тех или иных принципов и критериев справедливости, которые слабо поддаются объективизации или вообще не могут быть объективированы. Решения о справедливости или несправедливости в этом мире практически не ориентируются на мнения других индивидов. В этом мире очень важны эмоции, чувства, страсти, которым индивиды доверяются для конструирования своих решений о справедливости или несправед- 
ливости. Поэтому решения о справедливости или несправедливости в этом мире не всегда можно объяснить рационально. Тем не менее такие вдохновенные личности своей оригинальностью и самобытностью служат другим людям и помогают им находить общее благо, преодолевая и даже отбрасывая мешающие этому стандарты и стереотипы.

\section{Мир патриархальный}

В патриархальном мире решения о справедливости или несправедливости определяются положениями индивидов в социальных иерархиях, основанных на личных зависимостях, личных взаимоотношениях и взаимном доверии к своему социальному окружению. В этом мире малозначимы и редко используются средства оценивания справедливости по объективным, общезначимым для всех индивидов правилам, а доминируют правила, способствующие установлению и поддержанию иерархических отношений между индивидами. Очень значимыми для принятия решений о справедливости или несправедливости в этом мире являются внешние признаки принадлежности к тому или иному уровню той или иной социальной иерархии. За известными личностями внешние признаки принадлежности к уровням социальных иерархий нередко закрепляются пожизненно, препятствуя переоценкам справедливости или несправедливости их решений и поведения.

В патриархальном мире социальный порядок и согласие между индивидами, необходимые для достижения и поддержания справедливости, нередко устанавливаются обращениями к традициям, воплощающим установленные социальные иерархии. Поэтому в этом мире ценятся стабильность, приличия, правильное, нравственное поведение, преемственность, награды по заслугам от начальников и вышестоящих в социальных иерархиях лиц. Малозначимы универсальные, независящие от социальных иерархий нормы законов, точность и результативность в решении поставленных задач, достижении целей.

В патриархальном мире распространены представления о том, что в оценках справедливости необходимо ориентироваться на образцовое поведение известных, уважаемых лиц, занимающих вышестоящие позиции в социальных иерархиях, и доверять им. Вышестоящие лица, в свою очередь, являются авторитетами, достаточно информированы и несут ответственность за обеспечение справедливости среди простых людей. Поэтому наиболее значимые принципы и критерии справедливости проявляются в этом мире в решениях и действиях лиц, занимающих высшие позиции в социальных иерархиях. 


\section{Мир репутаций}

В мире репутаций решения о справедливости или несправедливости принимаются на основе общественного мнения, мнений лиц, референтных для тех или иных индивидов, а также на основе моды на такие мнения. Поэтому согласие по принципам и критериям справедливости в мире репутаций достижимо лишь при опоре на мнения других индивидов, а не на собственные. В этом мире известность определяет и уравнивает по уровням доверия к ним авторитеты в общественном мнении. Малозначимыми для идентификации таких авторитетов являются их объективные качества, такие как профессия или профессиональные достижения. А известность авторитетов обеспечивается их группами поддержки, клиентелами. И такая известность в принципе может быть достигнута любым индивидом, независимо от его позиции в той или иной социальной иерархии, например с помощью осуществления массовой коммуникации в свою поддержку. Между тем такие авторитеты как носители значимых принципов и критериев справедливости не имеют устойчивых свойств и качеств личностей, а все вещественные свидетельства доверия к ним являются временными. Авторитеты в мире репутаций непостоянны, при изменениях условий и ситуаций они могут очень быстро забываться и заменяться другими. Это приводит к высокой степени уязвимости для критики применяемых в этом мире принципов и критериев справедливости. Не очень приятным для авторитетов общественного мнения является и то, что обеспечение признания публики требует от них отказов от секретности и закрытости сведений о себе, своей частной жизни, а также отсутствия непонятности и загадочности в их поведении.

\section{Гражданский мир}

В гражданском мире наибольшую значимость имеют принципы и критерии справедливости, поддерживаемые не отдельными индивидами, а коллективами, объединениями граждан. И ценности тех или иных принципов и критериев справедливости во многом определяются тем, от каких коллективов они представляются. Но любые коллективы индивидов всегда включены в другие, объемлющие их коллективные образования, вплоть до всего человечества в целом, хотя реализуется гражданский мир всегда в рамках того или иного государства, наилучшим образом в демократическом государстве. 
В гражданском мире все индивиды, независимо от их личностных и иных качеств, в том числе национальность и этничность, включены в единый порядок справедливости, который реализуется отдельными коллективами. В этом мире собственная воля индивида подчиняется общей воле его коллектива и вышестоящих коллективов, что позволяет преодолевать разделяющие индивидов разногласия и достигать согласий по справедливости. Важнейшим критерием справедливости в гражданском мире является обеспечение общего блага членов коллективов, объединений граждан. В этом мире важны проявления солидарности и выражения общих интересов индивидов, отстаивание прав и свобод человека и гражданина, соблюдение законности, общей для всех граждан, процедур, протоколов и других формальностей. Эти формальности являются свидетельствами прав на доверие представляемым принципам и критериям справедливости, а также создают возможности контроля поведения представителей объединений.

\section{Мир рынка}

Социальное поведение индивидов в мире рынка определяется их желаниями обладать одними и теми же объектами, причем объектами редкими, а не общественными благами. Поэтому основой принципов и критериев справедливости в мире рынка являются эгоизм, но учитывающий границы его применения, конкуренция, осуществляемая по общим для всех правилам, и успешность получения благосостояния на её основе. Для реализации таких принципов и критериев в рыночном мире поддерживается свобода индивидов, их независимость от личных связей и социальных иерархий, чтобы они могли легко заключать рыночные сделки.

Качества индивидов, не относящиеся к качествам продавцов и покупателей, в мире рынка в расчет не принимаются. От общих мнений в рыночном мире следует воздерживаться. Споры в этом мире регулируются с помощью цен, выражающих уровни значимости желаний индивидов. Успешность в этом мире определяется достигнутым уровнем богатства, владением ценностями, имеющими рыночные цены. Поэтому и сами индивиды имеют рыночную ценность в этом мире: ценятся богатые, а бедные практически не имеют никакой ценности.

Принципы и критерии справедливости рыночного мира не учитывают ни границ, ни расстояний, ни времени, они действуют одинаково для любых рынков, включая национальные и мировые. Цены на рынках 
постоянно меняются, поэтому нестабильность в этом мире оценивается скорее позитивно, чем негативно, случай может принести и неудачу, и удачу, что оценивается как обеспечение справедливости. Согласие по справедливости в рыночном мире достигается через признание успехов или неудач индивидов в рыночной конкуренции, осуществляемой по признаваемым обществом правилам.

\section{Мир науки и техники}

Это мир, в котором индивиды оперируют техническими объектами и используют научные методы в своей деятельности. Принципы и критерии справедливости в мире науки и техники основываются на признании ценности научно-технического порядка с его качествами поддержки эффективности и результативности как индивидов, так и технических объектов, а также производительности производства. В этом мире ценятся нормальное функционирование производства, его польза для потребителей и соответствие их запросам. Правильное функционирование индивидов и технических объектов позволяет продолжить настоящее в будущее. Поэтому в мире науки и техники значимой ценностью является прогнозирование и планирование будущего, причем планирование реалистичное, основанное на применении научно обоснованных методик. В мире науки и техники значимыми ценностями являются потребительские качества вещей, а не их цена, как в мире рынка. Другим отличием от мира рынка является то, что в мире науки и техники необходимо учитывать границы, расстояния и время. В этом мире справедливо поддерживать способности, профессиональные компетенции, рабочую силу и трудовой потенциал индивидов, потому что их координация позволяет обеспечить эффективность производства и научных достижений. Здесь значимые ценности - обеспечение прогресса, инноваций и инвестиций в развитие, что сопровождается разрывами традиций.

\section{МИРЫ СПРАВЕДЛИВОСТИ РОССИЙСКИХ ГРАЖДАН}

Участники проведенных исследований использовали не все, но некоторые смыслы, принципы и критерии миров справедливости Болтански и Тевено. Это никогда не происходило по их инициативе, но осуществлялось вполне успешно, когда им предлагалось оценивать те или иные модельные или реально происходившие жизненные ситуации. 
Формулировки принципов и критериев справедливости участников исследований почти никогда не совпадали с описаниями миров Болтански и Тевено. По результатам проведенного анализа собранные в исследованиях формулировки принципов, критериев и конкретных обоснований справедливости и несправедливости осмыслялись и распределялись по типам исходя из их близости к описаниям тех или иных миров справедливости. В результате получились наборы характеристик миров справедливости в представлениях и оценках граждан - участников исследований, которые в кратком изложении представлены ниже.

Принципы и критерии мира вдохновения сравнительно редко использовались участниками исследований, в основном когда они приводили религиозные обоснования справедливости. Такие критерии не были конкретными, участники исследований относили их к возможностям достижения согласия между представителями тех или иных религиозных конфессий. Но для неверующих или относящихся к другим конфессиям граждан согласие по справедливости на принципах и критериях этого мира представлялось малореальным. Чуть больше участники исследований надеялись на то, что какие-то вдохновенные личности с высокими моральными качествами сумеют предложить решения тех или иных социальных проблем на основе общего блага. Тем не менее ни одной конкретной вдохновенной личности никто из них не назвал: они неизвестны участникам исследований.

Принципы и критерии мира патриархального постоянно применялись участниками исследований в обоснованиях их суждений о справедливости, в частности привязанность к социальному окружению, ориентация на личные отношения, заслуги перед государством, соблюдение традиций, общепринятых норм морали и нравственности. Большое значение участники исследований придавали воспитанности индивидов, их хорошим манерам, уважению к другим. Принципы и критерии этого мира можно оценить как наиболее понятные и наиболее часто используемые российскими гражданами.

Принципы и критерии мира репутаций сравнительно редко применялись участниками исследований. Они в целом признавали значимость общественного мнения и даже моды на оценивание того, что справедливо, а что несправедливо в той или иной жизненной ситуации. Но никакие лидеры общественного мнения не являлись для них референтными в сфере справедливости, ни на какие мнения известных личностей никто из участников исследований не ссылался. Не ссылались 
они и на героев тех или иных литературных произведений или кинофильмов. При этом нередко участники исследований высказывали доверие мнениям индивидов и общественному мнению, которые они узнавали из СМИ или интернета. В некоторых случаях участники исследований соглашались с мнениями неизвестных им индивидов, журналистов, блогеров. Мир репутаций осваивается российскими гражданами, его принципы и критерии справедливости получают у них определенное доверие, а вот лидеры общественного мнения - пока сравнительно редко.

Принципы и критерии гражданского мира упоминались участниками исследований в большинстве случаев в качестве желаемых, но пока не реализуемых. Это принципы и критерии, определяемые необходимостью осуществления общей воли широких социальных групп и даже большинства общества, обеспечения прав и свобод граждан и социальной солидарности между ними. Но сам термин «социальная солидарность» никто из них не использовал, сущность этого понятия никогда не формулировалась более или менее точно. Это свидетельствует о низком уровне социальной солидарности в российском обществе, притом что ее необходимость гражданами осознается.

Принципы и критерии мира рынка упоминались некоторыми участниками исследований, но почти всегда высказывалось несогласие с ними, в частности с эгоизмом индивидов, получением ими благосостояния только на основе рыночных взаимодействий без учета норм морали и нравственности. Недоверие вызывали у участников исследований принципы и критерии справедливости, основанные на конкуренции, потому что они не верили в честность конкуренции в российских условиях. Вместе с тем в дискуссиях на фокус-группах, когда высказывались предложения по справедливым решениям тех или иных социальных проблем, никогда не делалось попыток оценить их рыночные стоимости. А ведь невозможно реализовать то или иное предложение в социальной или экономической сфере при недопустимо высокой его стоимости. Например, на фокус-группах обсуждалась необходимость повышения несправедливо низкой оплаты наемного труда в нашей стране практически во всех отраслях. И вполне реалистично участники фокус-групп утверждали, что работодатели не будут этого делать, но сделать это должно государство, потому что оно должно заботиться о своих гражданах и обеспечивать их право на благополучную жизнь. По сути, это принципы справедливости патриархального мира, которые 
в ситуации рыночных отношений оказались ближе и понятнее участниками исследований, чем принципы мира рынка.

Принципы и критерии мира науки и техники редко упоминались участниками исследований, им сложно было связать справедливость с научно-техническим прогрессом, производительностью труда и даже квалификацией специалистов. Но для некоторых ситуаций такая связь в их суждениях обнаруживалась. Наиболее понятными участникам исследований были принципы справедливости, основанные на эффективности и ее способствовании прогрессу в той или иной сфере. Так, на одной из фокус-групп обсуждалась проблема применения жителями некоторых многоквартирных домов в городе методов потребкооперации для обеспечения обслуживания в жилищно-коммунальной сфере. Участники фокус-группы пришли к согласию, что было бы справедливо применять такой опыт, о котором рассказал один из них. Помехой в распространении такого опыта всеми считались органы власти, не заинтересованные в таком новшестве. В этом примере участники фокусгруппы применили принципы справедливости как мира науки и технологий (эффективность для обслуживания домов), так и гражданского мира (использование потребкооперации как объединения жителей-граждан для этой цели). Пример показывает, что российские граждане, в соответствии с теорией Болтански и Тевено, могут применять принципы разных миров справедливости для оценивания различных аспектов одной ситуации.

Участники и фокус-групп и полуформализованных интервью чаще всего уходили от обсуждений аспектов именно справедливости тех или иных ситуаций, которые им предлагались в качестве стимулов. Они чаще всего сосредоточивались на обсуждениях содержательных аспектов ситуаций, того, что необходимо было сделать для их разрешения. А обоснования справедливости вариантов разрешения этих ситуаций волновали участников исследований существенно меньше, они ориентировались в своих суждениях на некие правильности, удобства, обеспечение благосостояния граждан, что лишь косвенно можно было оценить в качестве принципов справедливости. Участники исследований признавали при этом, что невозможно обеспечить правильность и справедливость решений с точки зрения всех сторон этих ситуаций, и никакими решениями невозможно обеспечить удобство и поддержку благосостояния всех участников ситуаций. Поэтому в более или менее сложных реальных социальных ситуациях без обсуждений справедли- 
вости предлагаемых решений всегда будут находиться те, кто оценит принятые решения как несправедливые по отношению к себе.

Обсуждать принципы и критерии справедливости вместе с содержательными аспектами решений ситуаций у российских граждан не получается, что подтвердили проведенные в исследованиях фокус-группы. Эти дискуссии моделировали публичные обсуждения аспектов справедливости различных жизненных ситуаций, как гипотетических, так и реально происходивших. Последние нередко предлагали для обсуждений сами участники фокус-групп, потому что видели в них важные для себя аспекты справедливости и несправедливости. Тем не менее обсуждения гипотетических и реально происходивших ситуаций почти во всех фокус-группах сосредоточивались на вариантах их решений, на содержательных аспектах этих вариантов, а обсуждения того, насколько они справедливы, если и начинались, то прекращались довольно быстро. Это происходило без достижения согласий участников дискуссий и без попыток найти объединяющие всех принципы и критерии справедливости в конкретных ситуациях.

Было заметно, что участники дискуссий на фокус-группах редко оказывались способными понятно для других изложить свои принципы и критерии справедливости. И столь же редко они оказывались способными выслушать и понять предлагаемые другими принципы и критерии. Как правило, участники дискуссий на фокус-группах оценивали для себя внимание к аргументам и позициям оппонентов как форму согласия с ними. А согласие с оппонентами представлялось им неправильным, они скорее вступали в споры с ними с целью переубедить, поставить оппонентов на свои позиции, чем с целью понимания чужих позиций без принятия их для себя. Однако без понимания позиций оппонентов невозможно предложить им какие-то варианты справедливости, которые они могли бы принять, например, на основе общих ценностей. Поэтому на фокус-группах дискуссии о справедливости в конкретных жизненных ситуациях почти всегда заходили в тупик.

Можно представить себе достаточно простые жизненные ситуации, в которых все участники более или менее одинаково понимают принципы и критерии справедливости. И тогда они могут приходить к согласию по справедливым решениям ситуаций. Но большинство реальных жизненных ситуаций иные, более сложные, неоднозначные для оценивания разными категориями граждан. Дискуссии с предъявлениями оппонен- 
там различных принципов и критериев справедливости, ее обоснований, с пониманиями оппонентами друг друга могли бы способствовать достижению согласий в таких ситуациях. Но российские граждане, как показали проведенные исследования, не обладают умениями вести такие дискуссии, а потому вступают в них крайне редко и еще реже продуктивно, т.е. с достижениями согласий о справедливости.

Умения российских граждан вести продуктивные дискуссии о справедливости могли бы формироваться и развиваться в тех или иных социальных практиках публичных обсуждений различных проблем. Но такие дискуссии в современной России практически не проводятся, а в нередких публичных обсуждениях спорных ситуаций и конфликтов никогда не ставится целью достижение согласия по справедливости их решений. Участники таких дискуссий оказываются готовыми к согласию по справедливости только тогда, когда им представляется обоснованными принципы и критерии справедливости одного общего для них мира. Болтански и Тевено утверждали, что множественность принципов и критериев справедливости во множественных ее мирах «характеризует сложно структурированное общество» [Болтански, Тевено 2013: 79]. С этим утверждением французских социологов следует согласиться, и сделать вывод о том, что по этой характеристике современное российское общество не может считаться сложноструктирированным.

\section{ТРИ ФАКТОРА АРХАИЗАЦИИ В РОССИИ}

Существенной проблемой в обеспечении справедливости в современной России является архаизация пониманий и практик справедливости и гражданами, и органами власти, и элитами при ведущей роли высших должностных лиц органов власти. Для подтверждения этого вывода сначала представим три основных фактора архаизации - профессионально-именной социокод, сословность и раздаточную экономику [Римский 2020], а затем опишем их действие в сфере социальных практик справедливости.

В соответствии с концепцией А.С. Ахиезера [Ахиезер 2001: 89] архаизация понимается как «следование общества и органов государственной власти культурным образцам и программам, сложившимся в культурах, предшествующих современным» [Римский 2018: 151]. Архаизация проявляется во всех современных обществах и государствах в использовании ими опыта и знаний предшествующих поколе- 
ний, соответствующих стандартов и стереотипов восприятия и оценивания реальности, методов решений общественных и других проблем, эффективность которых проверена в прошлом. Но когда в этих стандартах, стереотипах и методах доминирует архаика, она становится препятствием для поиска и реализации решений сложных современных проблем, существенно отличающихся от решавшихся в прошлом [Римский 2020: 72-73].

Важнейший фактор архаизации общества и органов власти в современной России - приверженность профессионально-именному социокоду М.К. Петрова [Петров 1995; 2004]. Как известно, любая информация существует только в закодированном виде, представляющем ее форму. По этой форме при передаче информации в человеческой коммуникации ее получатели восстанавливают переданные им смыслы. Естественно, такое восстановление никогда не может дать смыслы, полностью идентичные исходным, ее источников. Результаты восстановлений смыслов информации во многом определяются особенностями кодов, используемых в человеческой коммуникации. Общая культура и общие социальные практики индивидов развивают и совершенствуют их умения и навыки декодирования получаемой информации, что позволяет им в большинстве случаев понимать друг друга и участвовать в совместной деятельности. Поэтому тип применяемого кодирования социальной информации является значимым фактором и самой человеческой коммуникации, и используемых ее участниками стандартов, стереотипов восприятия и оценивания реальности, а также методов решений общественных и других проблем.

Эта значимость способов кодирования социальной информации, названных М.К. Петровым социокодами, и привела к их изучению. Эти социокоды развивались в соответствии с особенностями стадий развития человечества. М.К. Петров выделил три основных типа социокода: личноименной, характерный для первобытных обществ, профессиональноименной, характерный для первых цивилизаций и сохранявшийся в Западной Европе в Средние века, и универсально-понятийный, возникший в Древней Греции и используемый развитыми странами Западной Европы примерно с XVI-XVII вв. [Римский 2018: 156-165].

Отметим, что в профессионально-именном социокоде индивид описывается принадлежащим к своей профессиональной группе, ремесло которой определяло его жизнь и, как правило, передавалось по наследству. А социальную интеграцию обеспечивают традиции, 
ритуалы, мифы, мораль и нравственность, а также государственная власть [Петров 1995: 197-198; 2004: 105-107]. Профессионально-именной социокод способствует поддержке стабильности использующих его обществ и государств, но только в условиях отсутствия резких изменений природных и социальных условий.

Универсально-понятийный социокод существенно повышает возможности адаптации к быстрым и не всегда предсказуемым изменениям условий существования. Этот социокод соединяет общественное и личное, общие понятия и частные решения конкретных проблем с их использованием, позволяет развивать науку в современном понимании - с выдвижением гипотез и их проверкой с помощью эмпирических методик. Более того, только универсально-понятийный социокод позволил сделать науку эффективным средством модернизации обществ и государств, внедрения и эффективного применения разнообразных технологий. В сложных ситуациях существования именно универсально-понятийный социокод позволяет его носителям достаточно эффективно находить и осваивать новые профессии, внедрять новые технологии, обеспечивать функционирование институтов современной рыночной экономики, обеспечивать права и свободы человека и гражданина. Поэтому только универсально-понятийный социокод оценивается нами как современный, а два других — как архаические [Римский 2020: 73-75].

Современные российские чиновники важнейший смысл своей деятельности видят в соблюдении дисциплины, подчинении своим начальникам и делегировании им многих своих прав и свобод при исполнении служебных обязанностей. Принятие решений всегда отдается на уровень высшей бюрократии, которая не имеет реальных возможностей глубоко вникать в возникающие проблемы, применять научно обоснованные методы для их анализа и формирования вариантов решений. Для решений таких проблем и высшая бюрократия, и исполнители в органах власти редко используют или вообще не используют диалоги, коммуникации с различными группами граждан и специалистов. Поэтому решения, принимаемые и исполняемые органами власти, скорее поддерживают своеобразную «бюрократическую игру», означающую формальное следование нормам законодательства с неформальным выходом за их пределы при необходимости (только для высших должностных лиц), а также следование формальным и неформальным правилам поведения в своей социальной среде. Кроме 
того, как высшие должностные лица, так и исполнители в системе государственного и муниципального управления в своих профессиональных практиках редко и с трудом используют смыслы, понятия и представления, относящиеся к научно обоснованным решениям общественно значимых проблем. Наука для них остается составляющей образования с не всегда понятной значимостью, но не инструментом их реальной профессиональной деятельности. Такие особенности их сознания и социальных практик можно объяснить приверженностью профессионально-именному социокоду, а не современному универсально-понятийному [Римский 2020: 76-77].

Профессионально-именному социокоду привержено и подавляющее большинство российских граждан, потому что они постоянно воспринимают архаические смыслы и представления, транслируемые им через СМИ, социальные сети и интернет-сайты высшими должностными лицами органов власти. Способствует закреплению приверженности граждан профессионально-именному социокоду и то, что они постоянно участвуют в исполнении принимаемых органами власти решений, представленных именно этим социокодом. Так, российские элиты постоянно демонстрируют гражданам свое одобрение обращенности в прошлое, а также поиск именно в этом прошлом вариантов решений современных проблем. Декларируемые элитами и органами власти возможности современных технологий для их решений на деле реализуются с существенными ограничениями, соответствующими архаическими представлениями о необходимости обеспечения стабильности во всех сферах, а не их развития. В современной российской ситуации новые по форме институты, нормы и правила используются для поддержания архаичных способов реализации политики и государственного управления [Римский 2018: 165-166].

В современном российском обществе и государстве заметны проявления сословности, хотя формально не существует никаких законодательных норм, явно описывающих те или иные сословия. Но в России действуют нормы, определяющие особые привилегии и права конкретных социальных групп за выполнение ими обязанностей служения государству, определенных государственных функций или обслуживание тех, кто эти функции выполняет [Римский 2020: 77].

Современные сословия отличаются от сословий древности и Средневековья особенностями служений государству и тем, как и какие сословия они обслуживают. Но современные сословия сохраняют глав- 
ный принцип организации обществ с доминированием профессионально-именного социокода: формирование сословий по традиции или целенаправленно государством, разделение общества по профессиям, сферам служений государству или обслуживаний других сословий, обеспечение доходов за эти служения [Римский 2020: 78].

Российское государство создало и продолжает создавать такие социальные группы, которые вполне логично определять как сословия. Такими сословиями не только по нормам законов, но и по неформальным правилам служения и поведения могут считаться социальные группы судей, прокуроров, полицейских, Росгвардии, высших должностных лиц государственной службы, военнослужащих и некоторые другие [Римский 2020: 77].

Помимо сословий, в российском обществе существуют и профессионально-отраслевые корпорации, которые государство либо создает как сословия, либо предоставляет им право освоения тех или иных ресурсов, имеющих государственную значимость. Нередко такие корпорации включают представителей разных групп и социальных статусов, объединенных общими интересами сохранения своих прав и привилегий. В этом отношении такие профессионально-отраслевые корпорации сходны с сословиями и потому далее не упоминаются. Кроме того, в современной России существуют также классы, выделяемые по уровням потреблений своих членов. Доходы классов определяются на рыночных основаниях, а не решениями органов власти, хотя органы власти регулируют их доходы [Римский 2020: 78].

Сословность проявляется и в том, что российское государство распределяет сословиям для выполнения ими своих функций различные ресурсы: нефть, газ, финансы, цифровые данные и др. За выполнение сословиями своих функций государство пропорционально значимости их служений распределяет его членам доходы в соответствии с их социальными статусами, ведь сословия социально неоднородны - в них есть и представители элит, и рядовые исполнители принятых решений. Такие доходы не являются рыночными, они определяются не по результатам труда, а именно по значимости служений [Римский 2020: 77].

В российской экономике интересы сословий реализуются в первую очередь, потому что это фактически интересы государства. Но эти сословные интересы определяют освоение доверенных сословиям ресурсов, но не их преумножение или развитие. Такая экономика не является рыночной, ее можно назвать «раздаточной». О.Э. Бессонова 
определяет эту экономику так: «Раздаточная экономика - экономическая система, в которой нерыночные механизмы играют доминирующую роль, а рыночные - вспомогательную. Модель раздатка включает отношения сдач-раздач, общественно-служебную собственность и административные жалобы в виде обратной связи, а модель рынка - это отношения купли-продажи, частная собственность и прибыль как сигнальный институт» [Бессонова 2018: 22].

Раздаточный характер российской экономики вполне согласуется с сословностью. Раздачи ресурсов по служениям, чинам и заслугам осуществляет государство, «сдачи» ресурсов для пополнения государственного бюджета осуществляют сословия и классы. Пропорции сдачраздач складываются в течение длительных периодов времени, и соблюдение этих пропорций обеспечивает динамическую стабильность общества и государства. Небольшие нарушения этих пропорций устраняются по результатам рассмотрений жалоб и доносов [Римский 2020: 79]. Но для устранения существенных нарушений у экономической и государственной системы нет инструментов. Поэтому российское государство согласованно с сословиями поддерживает эту архаичную социальную структуру общества и архаичную раздаточную экономику, смыслы которых наиболее адекватно представляются архаичным профессионально-именным социокодом.

\section{ДОМИНИРОВАНИЕ АРХАИКИ В ПОНИМАНИЯХ И ПРАКТИКАХ СПРАВЕДЛИВОСТИ}

Когда российские граждане думают о справедливости безотносительно к конкретным ситуациям, они в ответах на соответствующие исследовательские вопросы упоминают принципы и критерии справедливости из разных миров Болтански и Тевено. Но в ситуациях своей повседневности наши граждане чаще обосновывают справедливость принципами и критериями мира патриархального, которые следует относить к архаическим. В этом мире ценностями являются соблюдение социальных иерархий и традиций, а также поддержание личных отношений между обладающими той или иной властью и подчиняющимися этой власти. Справедливость в этом мире определяется общим благом, обеспечение которого требует соблюдения социальных иерархий, традиций, родственных и личных отношений между индивидами [Ковенева 2008: 11-14]. В наших исследованиях к этим принципам 
справедливости нередко добавлялись обеспечение взаимного уважения между людьми, правды и истины, честности в межличностных отношениях и соблюдение норм морали и нравственности в них. Честность выделялась отдельно от остальных норм морали и нравственности. Эти дополнительные принципы нами было решено относить также к патриархальному миру в силу схожести мотивов их использования в социальных практиках с мотивами использования принципов поддержания социальных иерархий, традиций, личных и родственных отношений.

В некоторых ситуациях, которые предлагались для оценивания, участники исследований использовали принципы и критерии справедливости рыночного мира, гражданского мира, а также мира науки и технологий. К таким принципам и критериям можно отнести, в частности, справедливость как эффективность, содействие развитию технологий, поддержание честной конкуренции на рынках, признание успеха в коммерческой деятельности, соблюдение прав и свобод граждан. Но, когда такие принципы и критерии высказывались некоторыми участниками исследований, многими другими они не признавались и отвергались в качестве принципов и критериев справедливости. Исключение составили принципы соблюдения прав и свобод граждан, с которыми все участники исследований всегда соглашались. И практически всегда между ними наблюдалось согласие в том, что такими критериями и принципами российские органы власти руководствуются нечасто.

Существенно чаще органы власти для конструирования справедливых с их позиций решений общественных проблем и конфликтов используют принципы и критерии патриархального мира: поддержание социальных иерархий, социальной стабильности, традиций, поощрения по заслугам и наказания за невыполнения обязательств и т.п. Определяют применение этих принципов и критериев, безусловно, высшие должностные лица органов власти, транслируя их исполнителям в самих органах власти через бюрократическую систему и гражданам через СМИ, социальные сети и интернет-сайты. Поэтому ведущую роль в доминировании архаичных патриархальных принципов и критериев в обществе и государстве играют высшие должностные лица органов власти.

Проведенные исследования показали, что российские граждане считают несправедливым существенные различия уровней благосостояния в обществе. Участники исследований не могли описать причины таких существенных различий, не могли сформулировать никаких 
реальных предложений по сближению уровней благосостояния различных социальных групп. Но в сословном обществе и в раздаточной экономике уровни благосостояния большинства социальных групп определяются раздачами ресурсов государством. А государство их раздает в соответствии со значимостями служений сословий и влиятельности входящих в них элитных социальных групп, не согласуя их с гражданами невысоких статусов. И сложности формулирования предложений по снижению степени дифференциации благосостояния в обществе в том, что и у граждан, и у высших должностных лиц органов власти, принимающих решения, в сознании нет представлений об организации общества и экономики на иных, не архаичных принципах. Фактически участники исследований высказывались за то, чтобы все имели равные права на получение раздатков от государства, т.е. чтобы этот раздаток реально осуществлялся по заслугам, а не в соответствии с высокими или низкими социальными статусами и влиятельностями. Но такие пожелания граждан не могут быть реализованы без отказа от архаики в экономике, социальной сфере и государственном управлении.

В условиях эпидемии нового коронавируса COVID-19 в нашей стране проявились новые подтверждения желаний и возможностей высших должностных лиц органов власти и сословий укрепить архаику, а не отказаться от нее. Так, в полном соответствии с принципами раздаточной экономики и сословности в условиях этой эпидемии российские органы власти стали раздавать государственные заказы организациям, находящимся на высших уровнях государственной иерархии, организовывать проекты, в которых только такие организации могли принимать участие. Государственные заказы существенно поддерживали функционирование таких организаций, что было несправедливо по отношению ко многим другим, например к большинству организаций малого бизнеса.

В компенсациях потерь от эпидемии и в мерах приостановки деятельности многих организаций и учреждений органы власти тоже отдавали явный приоритет тем из них, которые находятся на высших уровнях государственной иерархии. Эту поддержку от государства получили именно такие банки, нефтяные и газовые компании, авиаперевозчики, фармацевтические компании и аптечные сети, сетевые супермаркеты и некоторые другие. Государственную поддержку получили организации влиятельные, способные успешно лоббировать 
в органах власти свои интересы. Про такие организации прямо написано в соответствующих документах, что они «системообразующие».

При этом организации, находящиеся на низших уровнях государственной иерархии или вообще в нее не входящие, получили только отсрочки по кредитам, выплатам налогов, арендной платы и некоторым другим. Это, например, относится к бизнесу в сферах общественного питания, туризма, физической культуры и спорта, предоставления бытовых услуг населению и др. И примерно также поддержало государство своих граждан: для них только выплата в 10000 рублей на ребенка была невозвратной, а все остальные финансовые выплаты и льготы нужно будет со временем вернуть банкам. Самозанятые, как и граждане других государств, находящиеся на территории России, не получили никакой поддержки от государства. Иностранные граждане получили некоторую поддержку своих малых и средних бизнесов, если они являлись именно такими предпринимателями.

Патриархальный принцип принадлежности к соответствующей иерархии применялся и в осуществлении денежных выплат участникам лечения больных коронавирусной инфекцией. Так, водителям машин скорой помощи, которые работали на ставках в медицинских учреждениях, такие выплаты осуществили. Но перед эпидемией в ходе оптимизации здравоохранения органы власти требовали сделать большинство таких водителей работающими в транспортных организациях, предоставляющих услуги скорой помощи медицинским организациям. Так во многих лечебных учреждениях и было сделано. Таким внештатным водителям не были осуществлены выплаты за работы по перевозкам больных коронавирусной инфекцией на скорой помощи. Причина в том, что внештатные водители формально не выполняли государственных функций, и потому раздаток им был не положен. И водители, и медицинские работники такую ситуацию оценивали как несправедливую, т.е. они, в отличие от органов власти, в этой ситуации признавали скорее критерии справедливости гражданского мира и мира рынка, чем мира патриархального.

В осуществлении выплат врачам, медицинским работникам и водителям, участвовавшим в лечении больных коронавирусной инфекцией, были также заметны признаки сословности. В полном соответствии с сословным принципом для противостояния этой эпидемии использовались ранее созданные сословия - военные. Но президентом России была предпринята попытка создать новое сословие врачей и ме- 
дицинских работников с новыми привилегиями: дополнительными выплатами, бесплатным проживанием в отелях, бесплатными перевозками транспортом к местам работы и обратно и т.п. Однако это сословие фактически не было создано, потому что был нарушен важный принцип его образования. Служение в сословной системе должно осуществляться строго по иерархии подчиненности, поэтому представители новых сословий должны были служить не непосредственно президенту России или федеральной власти, а властям местным, у которых не всегда были финансовые средства для обеспечения назначенных президентом страны привилегий. Такое сословие было создано из врачей и медицинских работников государственных медицинских учреждений только в тех местах, где таких средств оказалось достаточно, например в Москве. И даже некоторые частные медицинские организации тоже были включены в эту систему, когда они смогли войти в московскую программу перепрофилирования своих лечебных учреждений на лечение от коронавирусной инфекции.

Проблема справедливости в современной России весьма значима для большинства общества, что было еще раз подтверждено проведенными исследованиями. В ситуации эпидемии коронавируса COVID-19 ярче проявились различия между принципами и критериями справедливости, признаваемыми гражданами и органами власти. Граждане менее органов власти привержены принципам и критериям патриархального мира и поддерживают принципы и критерии гражданского мира, чуть меньше - миров рынка, науки и технологий. Высшие должностные лица органов власти в сфере обеспечения справедливости не поддерживают и не развивают эти приоритеты граждан, а стремятся сохранить архаические сословность, раздаточную экономику и профессионально-именной социокод для трансляции соответствующих им смыслов и ценностей.

\section{Литература}

Ахиезер A. С. Архаизация в российском обществе как методологическая проблема // Общественные науки и современность. 2001. № 2. С. 89-100.

Бессонова О. Э. Институциональное развитие России: переход к контрактному раздатку // Мир экономики и управления. 2018. Т. 18, вып. 2. С. 21-34. https://doi.org/10.25205/2542-0429-2018-18-2-21-34.

Болтански Л., Тевено Л. Критика и обоснование справедливости: очерки социологии градов / пер. с фр. О.В. Ковеневой; науч. ред. перевода Н.Е. Копосов. М.: Новое литературное обозрение, 2013. 576 с. 
Ковенева О. В. Французская прагматическая социология: от модели «градов» К теории «множественных режимов вовлеченности» // Социологический журнал. 2008. № 1. С. 5-21.

Наумова Е. Социология «градов» Л. Болтански и Л. Тевено и «режимы вовлеченности» в капитализм // Социологическое обозрение. 2014. Т. 13, № 3. C. 246-251. URL: https://sociologica.hse.ru/data/2014/12/29/1103796350/1SocOb oz_13_3_12_Naumova.pdf (дата обращения: 14.11.2020).

Петров М. К. Искусство и наука. Пираты Эгейского моря и личность. М.: РОССПЭН, 1995. $140 \mathrm{c}$.

Петров М. К. Язык, знак, культура / вступит. ст. С.С. Неретиной. 2-е изд., стереотип. М.: Едиториал УРСС, 2004. 328 с.

Римский В. Л. Мечты о справедливости и представления о возможностях их реализации в современной России // Образы будущего России: желаемое возможное - необходимое: материалы Всерос. науч.-практ. конф. Москва, 8-9 июня 2016 г. / под общ. ред. А.Б. Ананченко. М., 2016а. C. 128-136. URL: http://mpgu.su/wp-content/uploads/2016/11/Obrazyi-budushhego.-Sbornik-statey.E\%60lektronnoe-izdanie.pdf (дата обращения: 14.11.2020).

Римский В. Л. Понимания и практики справедливости в российском обществе // Социология и общество: социальное неравенство и социальная справедливость (Екатеринбург, 19-21 октября 2016 года): материалы V Всерос. социол. конгресса / отв. ред. В.А. Мансуров. М.: Российское общество социологов, 2016b. C. 7720-7729 (DVD ROM).

Римский В. Л. Архаизация политических элит и государственного управления России // Власть и элиты / отв. ред. А.В.Дука. Т. 5. СПб.: Интерсоцис, 2018. С. $150-179$.

Римский В. Л. Справедливость от государства: ожидания и реальность // Власть и элиты. 2019. Т. 6, № 2. С. 156-175.

Римский В. Л. Информатизация и российская архаика // Вопросы теоретической экономики. 2020, № 4. C. 71-86. URL: http:/questionset.ru/files/ arch/2020/2020-N4/Rimsky_VTE_2020_4.pdf (дата обращения: 20.11.2020).

Тевено Л. Креативные конфигурации в гуманитарных науках и фигурации социальной общности // Новое литературное обозрение. 2006. № 77. С. 285-313. Thévenot, Laurent. L'Action au pluriel: Sociologie des régimes d'engagement. P.: Éditions La Découverte, 2006. 311 p. 


\title{
ARCHAISM IN ENSURING FAIRNESS IN RUSSIA V. Rimskiy
}

\author{
(vlrim@yandex.ru) \\ Moscow Psychological and Social University, \\ Moscow, Russia
}

Citation: Rimskiy V. Arkhaika v obespechenii spravedlivosti v Rossii [Archaism in ensuring fairness in Russia]. Vlast' i elity [Power and Elites], 2020, 7 (2): 129-152. (In Russian)

DOI: https://doi.org/10.31119/pe.2020.7.2.6

\begin{abstract}
The article presents the manifestations of archaism in ensuring fairness in modern Russia. The reasons for these manifestations are based on the results of empirical sociological studies of fairness in Russian society, which were carried out in 2019 and 2020. It is shown that the Russian archaism is largely determined by the combined action of a complex of three factors: the dominance of the professional and personal social code of $M$. K. Petrov, social estate status and distribution economy. At the same time, senior government officials play a leading role in consolidating archaism in social fairness practices. Examples of archaic manifestations in ensuring fairness during the COVID-19 coronavirus epidemic are given.
\end{abstract}

Keywords: fairness, unfairness, archaism, social estates, distribution economy, professional and personal social code.

\section{References}

Akhiezer A.S. Arkhaizatsiya v rossijskom obshhestve kak metodologicheskaya problema [Akhiezer A.S. Archaization in Russian society as a methodological problem]. Obshhestvennye nauki i sovremennost' [Social sciences and modernity], 2001, 2, pp. 89-100. (In Russian)

Bessonova O.E. Institucional'noe razvitie Rossii: perehod k kontraktnomu razdatku [The Institutional Development of Russia: Transition to Contractual Razdatok]. Mir jekonomiki i upravlenija [World of Economics and Management]. 2018, 18 (2), pp. 21-34. https://doi.org/10.25205/2542-0429-2018-18-2-21-34.

Boltanski L., Thévenot L. Kritika i obosnovanie spravedlivosti: Ocherki sociologii gradov [De la justification: Les economies de la grandeur]. Ed. by N.E. Koposov. Moscow: Novoe literaturnoe obozrenie, 2013. 576 p. (In Russian)

Koveneva O. V. Franczuzskaya pragmaticheskaya sociologiya: ot modeli «gradov» $\mathrm{k}$ teorii «mnozhestvenny`x rezhimov vovlechyonnosti» [French pragmatic sociology: from the "cities" model to the theory of "multiple modes of engagement"]. Sotsiologicheskiy zhurnal [Sociological Journal], 2008, 1, pp. 5-21. (In Russian) 
Naumova E. Sociologiya «gradov» L. Boltanski i L. Teveno i «rezhimy` vovlechennosti» v kapitalizm [Sociology of "grads" by L. Boltanski and L. Thevenot and "modes of involvement" in capitalism]. Sociologicheskoe obozrenie [Sociological review], 2014, 13 (3), pp. 246-251. Available at: https://sociologica.hse.ru/data/2014/12/29/1103796350/1 SocOboz_13_3_12_Naumova.pdf (accessed: 14.11.2020). (In Russian)

Petrov M.K. Iskusstvo i nauka. Piraty Egejskogo morya i lichnost' [Art and Science. Pirates of the Aegean Sea and personality]. Moscow: ROSSPEHN, 1995. 140 p. (In Russian)

Petrov M.K. Yazyk, znak, kul'tura. [Language, sign, culture]. Introductory article by Neretinova S.S. $2^{\text {nd }}$ ed. Moscow: Editorial URSS, 2004. 328 p. (In Russian)

Rimskiy V. L. Mechty`o spravedlivosti i predstavleniya o vozmozhnostyax ix realizacii v sovremennoj Rossii [Dreams of fairness and ideas about the possibilities of their implementation in modern Russia]. In: Obrazy 'budushhego Rossii: zhelaemoe vozmozhnoe - neobxodimoe. Materialy' Vserossijskoj nauchnoprakticheskoj konferencii. Moscow, 8-9 iyunya 2016 g. [Images of the future of Russia: desired - possible necessary. Materials of the All-Russian Scientific and Practical Conference. Moscow, June 8-9, 2016]. Ed. by. A.B. Ananchenko. Moscow: Moscow State Pedagogical University; Institute of History and Politics, 2016a, pp. 128-136. Available at: http:// mpgu.su/wp-content/uploads/2016/11/Obrazyi-budushhego.-Sbornikstatey.E\%60lektronnoe-izdanie.pdf (accessed: 14.07.2019). (In Russian)

Rimskiy V. L. Ponimaniya i praktiki spravedlivosti v rossijskom obshhestve [Understanding and practice of justice in Russian society]. In: Sociologiya i obshhestvo: social 'noe neravenstvo i social 'naya spravedlivost' (Ekaterinburg, 19-21 oktyabrya 2016 goda) [Sociology and Society: Social Inequality and Social Justice]. Ed. by V.A. Mansurov. Moscow: Rossijskoe obshhestvo sociologov, 2016b, pp. 7720-7729. (DVD ROM). (In Russian)

Rimskiy V. L. Arxaizaciya politicheskix e' lit i gosudarstvennogo upravleniya Rossii [Archaization of political elite and public administration of Russia]. Power and Elites. Ed. by A. Duka. Vol. 5. St. Petersburg: Intersotsis, 2018, pp. 150-179. (In Russian)

Rimskiy V. L. Spravedlivost' ot gosudarstva: ozhidaniya i real'nost' [Fairness from the state: expectations and reality]. Power and Elites. Ed. by A. Duka, 6 (2), pp. 150-179. (In Russian)

Rimskiy V. L. Informatizaciya i rossijskaya arxaika [Informatization and the Russian archaizm]. Voprosy' teoreticheskoj e'konomiki [Questions of Theoretical Economics], 2020, 4, pp. 71-86. Available at: http://questionset.ru/files/ arch/2020/2020-N4/Rimsky_VTE_2020_4.pdf (accessed: 20.11.2020). (In Russian)

Thévenot L. Kreativny'e konfiguracii v gumanitarny`x naukax i figuracii social'noj obshhnosti [Creative configurations in humanitarian sciences and social community figurations]. Novoe literaturnoe obozrenie [The New literary review], 2006, 77, pp. 285-313. (In Russian)

Thévenot L. L’Action au pluriel: Sociologie des régimes d'engagement. Paris: Éditions La Découverte, 2006. 311 p. 